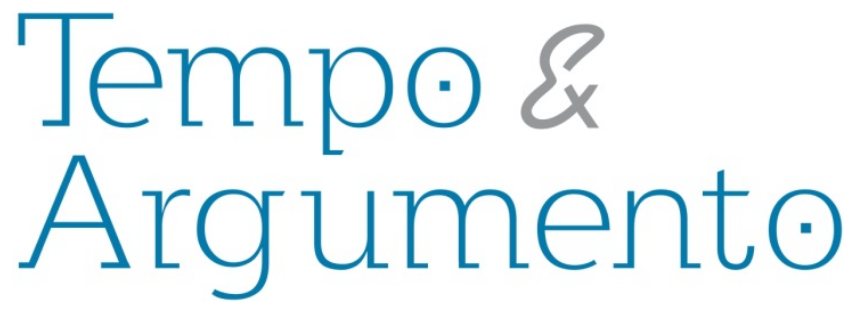

\title{
Philippe Ariès e seus arquivos: da memória do historiador à do militante
}

\section{Resumo}

Este artigo tem como objetivo discutir a trajetória do historiador Philippe Ariès através da análise dos "arquivos Philippe Ariès" que foram reunidos no final dos anos 90. Esta dividido em 3 partes: na primeira parte foi feito uma breve exposição das grandes etapas do itinerário de Philippe Ariès entre a cultura política e a vocação de historiador; em um segundo momento foi aprofundado como se constituíram seus arquivos privilegiando a figura do historiador sem mascarar o militante, uma vez que as duas identidades são fortes. E por fim, analisaremos as condições da sua atualização e as tensões suscitadas pelo retorno da figura do militante sobre o historiador sobretudo com a recepção de suas obras póstumas a partir de 1986.

Palavras-chave: Arquivos particulares. Trabalho de historiador. Cultura política.

\author{
Guillaume Gros \\ Historiador, \\ Pesquisador associado do \\ FRAMESPA, Universidade de \\ Toulouse le Mirail - França. \\ grosg@free.fr
} Tradução

\section{Fernando Coelho}

Mestre em Estudos da Tradução e doutorando em Linguística na

Universidade Federal

de Santa Catarina

zeffiretto@gmail.com

\section{Para citar este artigo:}

GROS, Guillaume. Philippe Ariès e seus arquivos: da memória do historiador à do militante.

Revista Tempo e Argumento. Florianópolis, v. 5, n.9, jan./jun. 2013. p. 357 - 377. 


\title{
Philippe Ariès and his files: from the memory of the historian to that of the militant
}

\begin{abstract}
This article aims to discuss the trajectory of the historian Philippe Ariès by means of the analysis of "Philippe Aries files", which were gathered in the late 1990s. It is divided in three parts: the first part makes brief exposition of the major stages of the journey of Philippe Ariès between political culture and the vocation of the historian; the second explains how his files were constituted, privileging the figure of the historian without masking the militant, since the two identities are strong. Finally, we analyze the conditions for their update and the tensions raised by the return of the figure of the militant over that of the historian mainly considering the reception of his posthumous works from 1986.
\end{abstract}

Keywords: Particular archives. History of childhood. Political culture. Militancy. 

parte tradicional, histórica, e a parte moderna, política. Eu não conseguia separá-las e eu sofria por isso. A história - esta nova história - me liberou desta tensão e me permitiu encontrar livremente as minhas origens."”

\section{1) Quem era Philippe Ariès?}

\section{O difícil reconhecimento da condição de historiador}

Autor de várias obras importantes no século XX sobre a história das populações francesas, a criança e a vida familiar, a morte e a vida privada, Philippe Ariès é reconhecido como um historiador de primeira plana, próximo da corrente historiográfica dos Annales, ao lado de Fernand Braudel, Emmanuel Le Roy Ladurie ou Jacques Le Goff.

É possível por isso reduzir Philippe Ariès apenas à condição de historiador? Com efeito, ele não pertenceu, no sentido estrito do termo, à corporação dos historiadores profissionais. Diretor de um centro de documentação do Institut des fruits et agrumes coloniaux (IFAC), desde 1943, ele esteve nesta atividade até a sua admissão na École des hautes études en sciences sociales (EHESS), em 1978, ao fim de sua carreira profissional e quando já havia redigido o essencial de sua obra.

Enfim, outra singularidade de Philippe Ariès, sua vocação de historiador se afirmou no contato com uma cultura política da Action française perfeitamente assumida, que Ihe permitiu posicionar-se, em uma perspectiva tradicionalista, como pioneiro da história das mentalidades através do desvio pela demografia²

\footnotetext{
${ }^{1}$ Philippe Ariès, « Comment devient-on historien ? », Cahiers d'histoire immédiate, Toulouse, $\mathrm{n}^{\circ}$ 39, printemps 2011, p. 19.

${ }^{2}$ Cf. Guillaume Gros, «Philippe Ariès, entre traditionalisme et mentalités. Itinéraire d'un précurseur »,
} 
Se, como se verá adiante em detalhe, a lógica da classificação de seus arquivos privilegia a figura do historiador, a sua diversidade mostra que eles são tão indissociáveis de um caminho político e intelectual amplamente evocado pelo principal interessado desde 1954, em Le Temps de l'histoire, depois no fim de sua vida em Un Historien du dimanche (1981), um itinerário que se enquadra no campo de uma direita tradicionalista.

Quando o que chamamos os "arquivos Philippe Ariès" foram reunidos, por nossos cuidados, em vista de uma classificação sistemática a partir do fim dos anos 90, em duas grandes etapas, paradoxalmente, as tensões em torno da memória política do historiador apareceram primeiramente, com um documento exterior a esses arquivos propriamente ditos, na ocasião da publicação de seus artigos, no momento da guerra da Argélia, na Nation française, pela historiadora Jeannine Verdès-Leroux ${ }^{3}$.

Os artigos de Philippe Ariès, na Nation française, suscitaram uma crítica virulenta, num artigo do Figaro, da parte de Emmanuel Le Roy Ladurie ${ }^{4}$, figura maior da Ecole des Annales que havia no passado nomeado Philippe Ariès.

Comprometendo na França a posteridade do historiador, esta tomada de posição é acompanhada no plano historiográfico de uma reavaliação da figura do militante político feita por Patrick H. Hutton ${ }^{5}$ e Guillaume $\operatorname{Gros}^{6}$. Contudo, a dimensão política não é vista de modo nenhum de um ponto de vista político, mas através do prisma do peso da cultura tradicionalista de Philippe Ariès na construção de uma obra histórica pioneira e original. Esta articulação entre a cultura política e a obra do historiador foi esboçada por Roger Chartier, na sua introdução à reedição de Le Temps de l'histoire, pela Seuil, em 1986, em um longo prefácio que se apoiou em uma parte do que iria tornar-se os arquivos Philippe Ariès. Roger Chartier prossegue esta iniciativa em 1993, na sua introdução a uma

\footnotetext{
Vingtième siècle. Revue d'histoire, $\mathrm{n}^{\circ}$ 90, avril-juin 2006, pp. 121-140.

${ }^{3}$ Cf. Philippe Ariès, Le Présent quotidien 1955-1966, Ed. du Seuil, coll. « XX ${ }^{e}$ siècle », 1997.

${ }^{4}$ Cf. Emmanuel Le Roy Ladurie, « Philippe Ariès : un Historien en réaction », Le Figaro, 22 mai 1997.

${ }^{5}$ Cf. Patrick H. Hutton, Philippe Ariès and the Politics of French Cultural history, Amherst, Boston, University of Massachusetts Press, 2004, p. 244.

${ }^{6}$ Cf. Guillaume Gros, Philippe Ariès (1914-1984). Un traditionaliste non-conformiste de l'Action française à l'Ecole des hautes études en sciences sociales, Villeneuve d'Ascq, Presses Universitaires du Septentrion, 2008, p. 348.
} 
Ariès entre cultura política e vocação de historiador ${ }^{7}$, veremos como se constituíram seus arquivos privilegiando a figura do historiador sem mascarar o militante, uma vez que as duas identidades são fortes.

Por fim, analisaremos as condições da sua atualização e as tensões suscitadas pelo retorno da figura do militante sobre o historiador sobretudo com a recepção de suas obras póstumas a partir de 1986.

\section{Singularmente livre entre história e política}

As indicações dadas aqui acerca do itinerário político de Philippe Ariès, separadas em cinco momentos, não devem, em hipótese alguma, ser dissociadas do nascimento de uma vocação de historiador, uma vez que a imbricação entre política e história é muito íntima em Philippe Ariès.

No início do século XX, o jovem Philippe se encontra em uma família realista cuja cultura pré-existe à Action française. Este culto das tradições não impede de modo nenhum a família Ariès de viver a modernidade no plano profissional, sobretudo no que diz respeito ao pai do historiador, engenheiro que participou do desenvolvimento da energia elétrica. Após a infância, Philippe Ariès se engaja no movimento de Charles Maurras, primeiro com os secundaristas e universitários da Action française, depois colaborando com o Étudiant français, entre 1936 e 1939, em que redige cerca de vinte artigos $^{8}$. Ele participa também das manifestações de rua e dos ciclos de palestras do Institut de formation d'Action française. O terceiro momento é o da ocupação durante a Segunda Guerra Mundial. Philippe Ariès participa de algumas ações da Revolução nacional. Ele ensina principalmente, até o verão de 1942, nos Centros de juventude e na

\footnotetext{
${ }^{7}$ Cf. notre article: G. Gros, «Culture politique et vocation d'histoire chez Philippe Ariès », Cahier d'histoire immédiate, op. cit., pp. 23-36.

${ }^{8}$ Cf. a bibliografia exhaustiva desses artigos, in G. Gros, Philippe Ariès..., P. U. du Septentrion, op. cit. p. 294.
} 

françaises, no qual ele combate o que chama de "resistencialismo". Finalmente, último engajamento, entre 1955 e 1966, ele trabalha no semanário monarquista, La Nation française. No contexto da guerra da Argélia, Philippe Ariès adota uma posição original mas difícil de sustentar: apoio a de Gaulle, a partir de 1958, por fidelidade ao conde de Paris, e depois, a partir de1960 e sobretudo de 1961, virulência de um antigaulismo que se confunde com a defesa dos amigos próximos da OAS (Organisation de l'armée secrète).

A este quadro, portanto, superpõe-se o nascimento de um historiador que busca afastar-se da política precisamente pela história, e isto desde o período de Vichy, em que, na sequência de seu primeiro livro, Traditions sociales dans les pays de France, ele se lança à sua Histoire des populations françaises et de leurs attitudes devant la vie que ele redige, como um anacoreta, entre a metade de 1944 e 1945.

A revelação da demografia e do que ele chama de uma "história das estruturas", ou uma "história subterrânea" que se esforça por identificar os comportamentos e as atitudes diante da vida e da morte, consagra o início de uma vocação. Ele empreende, desde o pós-guerra, compreender as condições de nascimento desta vocação de historiador a partir de seu percurso pessoal em Le Temps de l'histoire, obra que é a um só tempo uma reflexão historiográfica e epistemológica. Desta obra, publicada em 1954, longe da universidade, Roger Chartier não hesita em concluir que é "sem dúvida o primeiro livro escrito por um historiador não pertencente à 'école' em que se manifesta uma compreensão tão aguda da ruptura representada pelos Annales, a obra de Bloch e a de Febvre $[\ldots] "$ "..

Da história dos costumes, um instante vista a partir da parte de sua Histoire des populations françaises dedicada à emergência da "Criança na família", Philippe Ariès empreende a história do sentimento familiar, que dá nascimento a Enfant et la vie familiale sous l'Ancien régime (1960), na coleção que ele dirige na editora Plon

\footnotetext{
9 Roger Chartier, "L'amitié de l'histoire », préface, in Le Temps de l'histoire, Paris, Seuil, 1986, (1 ère éd. Rocher, 1954), p. 18.
} 

educação.

Os sobressaltos da independência da Argélia e as querelas em torno da OAS acabam por afastá-lo definitivamente da política, e nisso ele é ajudado, veremos, pelo pintor de origem polonesa, Joseph Czapski (1896-1993).

Em razão do sucesso americano de Enfant et la vie familiale, Philippe Ariès é conhecido na França pelos historiadores universitários e sobretudo por Michel Winock, que lança o ciclo das reedições da editora Seuil a partir de 1971. Após uma primeira versão americana dos Essais sur l'histoire de la mort en occident (Seuil, 1975), publicada primeiramente sob o título Western Attitudes toward Death: From the Middle Ages to the Present ${ }^{11}$, Philippe Ariès é absorvido pelo Homme devant la mort, que o consagra em 1977 entre os historiadores das mentalidades.

Midiático, dando-se bem com as câmeras, e dotado para a conversação, ele amplifica o sucesso de sua obra pela evocação de seu itinerário político na narrativa agradável de um Historien du dimanche (Seuil, 1980) sob a forma de entrevistas com Michel Winock. Impõe-se, então, nas mídias a figura de um espírito não-conformista, cujos livros têm tiragens muito numerosas para um historiador.

Esta dinâmica editorial se prolonga, numa menor medida, após sua morte, com as reedições, pela editora Seuil, de Le Temps de l'histoire (1986), depois dos Essais de Mémoire (1994) e finalmente do Présent Quotidien (1997), três obras que indiretamente têm como fonte o que se pode chamar de os arquivos de Philippe Ariès.

\footnotetext{
${ }^{10} \mathrm{Cf}$. Philippe Ariès, Centuries of Childhood: a social history of family Life, New York, Random House, 1962.

${ }^{11}$ Baltimore, Johns Hopkins University Press, 1974.
} 
Agrupados numa dezena de caixas de papelão, os documentos que figuram nos “arquivos Philippe Ariès” não foram selecionados diretamente pelo principal interessado, mas resultam da escolha de sua irmã, Marie-Rose Ariès, na lógica da identidade do historiador que segue o trabalho de classificação realizado pela esposa do historiador, enquanto vivia, em torno de cada livro publicado.

A morte da mulher de Philippe Ariès, logo depois da dele, criaram uma situação complexa em torno do aspecto material dos bens do historiador que se dividiam entre seu domicílio em Maisons-Laffitte (Yvelines) e o da rua da Echarpe, em Toulouse, onde ele estava a ponto de se instalar definitivamente.

Uma grande parte dos documentos de Philippe Ariès, em particular sua biblioteca, se dispersou, como acontece frequentemente, no momento da concretização da sucessão e da venda de seu domicílio de Yvelines.

Contudo, antes desta dispersão, Marie-Rose Ariès - legatária universal - , irmã mais nova do historiador, reuniu documentos pessoais e familiares e ainda outros ligados à sua atividade de historiador. Até o fim dos anos 90, estes documentos podiam ser consultados na casa de Marie-Rose Ariès, em Chesnay (Yvelines). Dito isto, os documentos de caráter privado, sobretudo as correspondências familiares, não estão compreendidos, pois a irmã do historiador não deseja que se penetre na intimidade da família. Por outro lado, era possível consultar um conjunto de arquivos classificados de maneira muito rigorosa pela esposa de Philippe Ariès, Primerose, enquanto estava viva, em função dos títulos publicados pelo historiador a partir de 1948, com a Histoire des populations françaises.

Por outro lado, com a concordância de Marie-Rose Ariès, a editora Seuil, por intermédio do editor Jean-Pi La Pierre e do historiador Roger Chartier, reuniu, por sua vez, alguns documentos ${ }^{12}$ na perspectiva de uma publicação de textos inéditos ou pouco

\footnotetext{
${ }^{12}$ Entre esses documentos, citamos sobretudo dois manuscritos inéditos, entre os quais o manuscrito para a
} 
conhecidos do historiador. Alguns dentre eles foram editados na coletânea Essais de Mémoire (1993) por Roger Chartier. Reunidos pela Seuil em uma pasta, esses documentos podiam então ser vistos, na Seuil, na rua Guénégaud, 75006. No fim dos anos 90, MarieRose Ariès aceitou confiar os arquivos do historiador aos Arquivos Nacionais por intermédio de Brigette Mazon, responsável pelos arquivos na École des hautes études en sciences sociales, instituição onde Philippe Ariès havia obtido, ao fim de sua vida, um posto de professor.

A pasta da Seuil foi então devolvida à sede da EHESS, na avenida Raspail, onde, para fins de uma tese de doutorado em história, no Institut d’Études Politiques de Paris, nós empreendemos realizar, a conselho de Brigitte Mazon, um primeiro inventário que constitui um anexo à nossa tese defendida em janeiro de 2002 e disponível na biblioteca da Science Po ${ }^{13}$.

Grande parte deste inventário foi publicada em uma versão reduzida de nossa tese em 2008, nas Presses Universitaires du Septentrion ${ }^{14}$.

Nesse meio tempo, na ocasião da sua mudança de domicílio do Chesnay para Chauvigny (perto de Poitiers), Marie-Rose Ariès exumou de seu porão mais duas caixas, as quais continham essencialmente fichas de trabalho do historiador e uma parte do manuscrito de Homme devant la mort. Essas duas caixas, uma sobre a criança e a vida familiar e a outra sobre a morte, foram então integradas aos arquivos e em seguida repertoriadas no novo inventário, que recebeu uma introdução substancial ${ }^{15}$.

\footnotetext{
titulação em estudos superiores do historiador, um ensaio sobre Alfred de Musset e textos mais recentes, o mais das vezes conferências.

${ }^{13} \mathrm{Cf}$. «Inventaire des archives Philippe Ariès » (60 pages) in Guillaume Gros, Philippe Ariès (1914-1984). Un traditionaliste non-conformiste : de l'Action française à l'École des hautes études en sciences sociales, sob a dir. de Serge Berstein, IEP de Paris, 2002, 3 vol.

${ }^{14}$ Cf. Guillaume Gros, Philippe Ariès (1914-1984). Un traditionaliste non-conformiste..., op. cit., pp. 275-325.

${ }^{15} \mathrm{Cf}$. Guillaume Gros, ver ref. em B. Mazon.
} 
Primerose Ariès, ao longo de carreira de seu marido, o acréscimo dessas duas caixas reforça a identidade dos arquivos que põe em primeiro plano a figura do historiador em detrimento do militante. Com apoio nesta identidade, os arquivos compreendem, no que diz respeito sobretudo aos textos manuscritos, uma maioria de textos que pertencem essencialmente ao seu período de conferencista, a partir da metade dos anos setenta, sua produção ligada ao seu seminário da École des hautes études en sciences sociales. Dito isto, uma parte desses textos, feita de grandes alusões ao seu itinerário político à imagem daquele que nós publicamos na revista Cahier d'histoire immédiate: "Como alguém se torna historiador?" e do qual este trecho é revelador do estilo de Philippe Ariès:

“Então, desenvolve-se neste meio familiar uma ideologia política. Esta ideologia era espontaneamente inspirada pelo culto do passado e das pequenas regiões: o que nós chamaremos a tradição, e pelo ódio da revolução e daquilo que Ihe resultou: a democracia igualitária. Quer dizer que se era realista. [...] A esta ideologia tradicional e realista, acresceu-se no século XX sob a influência de um Maurras meridional uma ideologia antidemocrática e nacionalista de origem parisiense antissemita e xenófoba.

Essas duas ideologias estiveram ligadas à corrente de extrema direita que desempenhou um papel importante na França dos anos vinte e trinta: Barrès, Maurras, e quem foi banido depois da segunda guerras. Não sobrou quase nada.

Distingo aqui cuidadosamente os dois componentes desta ideologia: uma tradicional, outra moderna e nietzschiana. Em minha casa e na minha infância, elas não eram distinguidas. Elas eram confundidas. Eu mesmo, há poucos anos que eu me dei conta daquilo que esta mistura tinha de contraditório e de explosivo. Contudo, em minha juventude, eu sentia no fundo de mim mesmo um mal-estar. Com efeito, na casa dos meus camaradas, o elemento político e nietzschiano da mistura sobrelevava cada vez 

que reúnem uma grande parte de sua produção de historiador sob a forma de contribuições, de artigos e de separatas, desde suas primeiras publicações na revista Population, do INED (Institut national des études démographiques) em 1949. Contudo, além dos artigos políticos ausentes, tampouco dispomos das numerosas notas de leitura - o mais frequentemente sobre obras de historiador - que ele entrega desde 1945 às revistas J'ai Lu, La Revue française de l'Elite, e La Table Ronde ${ }^{17}$.

Ao classificar esses arquivos, conservamos então a lógica dos arquivos reunidos, privilegiando o historiador. Na correspondência doravante organizada por ordem alfabética e não mais por dossiês em função dos livros, toda vez que isto foi possível, nós assinalamos o conteúdo da carta precisando de maneira abreviada a obra à qual ele se relaciona. Depois, com as diferentes recensões obtidas a partir dos dossiês das obras de Philippe Ariès, nós estabelecemos a partir da Histoire des populations françaises (1948) dossiês de recepção para cada obra. Embora não se possa almejar a exaustão, este corpus documental no interior do inventário, autônomo em si, constitui uma ferramenta preciosa para compreender o caminho de uma obra no plano cronológico, identificar melhor os diferentes estratos de sociabilidades e individuar as etapas que levaram à conquista da notoriedade.

Vê-se, portanto, que os arquivos não são de modo nenhum redutíveis apenas ao historiador, à medida que Philippe Ariès não dissocia o historiador e sua cultura política. Sua extrema diversidade revela painéis inteiros do universo intelectual e político de Philippe Ariès, das sociabilidades da Action française dos anos trinta à Nation française, passando pelas da Académie des sciences Morales et politiques ou do Institut national des

\footnotetext{
${ }^{16}$ Philippe Ariès, « Comment devient-on historien ? », op. cit., p. 17-18.

${ }^{17}$ Para um inventário completo desses artigos, veja-se nossa bibliografia, Guillaume Gros, Philippe Ariès..., 2008, op. cit., pp. 294-302. No que diz respeito aos artigos políticos, apenas foram publicados os artigos da Nation française, com poucas exceções, no Présent quotidien (Seuil, 1997).
} 


\section{Sobre dois manuscritos e sobre a correspondência}

Entre os textos manuscritos, destacamos em particular dois textos da juventude, retidos na primeira triagem de Roger Chartier, mas por fim não publicados na coletânea Essais de Mémoire. O primeiro é aquele pelo qual ele obteve seu diploma de estudos superiores, defendido em junho de 1936 na Sorbona, Les Commissaires-examinateurs au Châtelet au $\mathrm{XVI}^{e}$ siècle ${ }^{18}$ do qual Philippe Ariès utilizou certo número de conclusões em uma conferência do Institut d'Action française, cujo texto foi publicado posteriormente na revista dos estudos da Action française ${ }^{19}$. O outro é um ensaio literário sobre Alfred de Musset, L'Amour et l'amour propre dans la Confession d'un enfant du siècle (verão de 1938), reproduzido e anexado à nossa própria tese ${ }^{20}$. Este ensaio, por vezes um pouco escolar, insere-se na problemática maurrasiana da crítica do romantismo tal como Maurras a desenvolveu em seu ensaio intitulado Les Amants de Venise (1920) sobre as relações entre Georges Sand e Alfred de Musset. Ele nos informa sobre as aspirações do jovem Ariès, que frequenta então o salão da viúva de Jacques Bainville e que se vê tentado, provavelmente, por uma carreira literária.

Primerose Ariès revela os círculos de sociabilidades do historiador. Podem distinguir-se dois grandes momentos cuja linha de separação é o início da notoriedade do historiador.

No período anterior a 1970, pode-se tentar hierarquizar os diferentes autores. Um primeiro círculo é composto de personalidades ligadas à Académie des sciences morales et politiques e aos salões literários de Daniel Halévy e de Gabriel Marcel, dos quais participam Léon Bérard, Henri Boegner, que ainda dirige o Cercle Fustel de

\footnotetext{
${ }^{18}$ Datilografado, este texto de 203 páginas traz uma bibliografica manuscrita e numerosas notas de rodapé, o que nem sempre facilita a sua leitura, já complicada em razão dos inúmeros erros tipográficos.

${ }^{19}$ Cf. Philippe Ariès, « Le roi arbitre des libertés", I’Etudiant français, 10 de maio de1937.

${ }^{20}$ Cf. Guillaume Gros, Philippe Ariès (1914-1984).op. cit., 2002, t. 3, pp. 641-670. As 120 páginas são manuscritas, salvo as 3 páginas da introdução datilografadas.
} 

seu intermédio, em relação com Alfred Sauvy e o Institut national des études démographiques, que é então a única instituição a dar valor aos primeiros trabalhos do historiador sobre a demografia e a contracepção.

Após 1970, com a notoriedade, as cartas de historiadores são mais numerosas embora algumas sejam simples cartas de agradecimento por uma obra enviada. Além do seu aspecto convencional, estas respostas permitem medir a nova legitimidade dos trabalhos de Philippe Ariès: citemos sobretudo as de Pierre Guiral, Maurice Agulhon, Paula Veyne e Michel Vovelle, ou ainda de Pierre Chaunu, Jean Delumeau, Jacques Le Goff, Emmanuel Le Roy Ladurie, André Burguière e Georges Duby. Indo além das trocas acadêmicas entre historiadores, é preciso ler a belíssima carta pessoal de Pierre VidalNaquet a Philippe Ariés de 1964 que evoca, em pano de fundo, as tensões em torno da Argélia, revelando nestes dois homens, conquanto afastados no que diz respeito à política, uma mesma concepção da história e do engajamento político indissociável de certa prática da história. Portanto, não é surpreendente encontrar uma pasta específica intitulada "Nation française", na qual Philippe Ariès mantém cartas calorosas de alguns de seus amigos de juventude, numa ruptura em relação à linha editorial da revista combativa que Pierre Boutang dirige entre 1955 e 1966. Reunindo também cartas de leitores da Nation française, revelam-se as tensões que percorrem a comunidade política maurrasiana à qual Philippe Ariès pertence, em razão da guerra da Argélia e de suas consequências após os acordos de Evian.

Deste ponto de vista, a correspondência do historiador com o pintor Joseph Czapski traz uma luz decisiva para compreender as tensões que animam Philippe Ariès de maneira mais profunda.

Uma referência da intelligentsia polonesa vivendo definitivamente na França desde 1945 após uma educação cosmopolita e uma história pessoal movimentada desde a

\footnotetext{
${ }^{21} \mathrm{O}$ prosseguimento deste intercâmbio mostra a força dos laços entre P. Ariès e o Cercle Fustel de Coulanges, no qual participou ativamente no começo da Ocupação.
} 
colagens e desenhos. Entres estas, uma delas, intitulada pelo pintor Lettre d'un métèque, constitui à maneira de um diário um precioso resumo do estado de espírito dos dois amigos de um modo acalorado. ${ }^{22}$

\section{3) O uso dos arquivos e os choques com a memória política}

\section{O ciclo das reedições: uma abordagem mais histórica do militante.}

Após sua morte, como foi dito, a editora Seuil procede, entre 1986 e 1997, a três novas publicações: uma reedição de um texto esgotado e a edição de duas novas obras de Philippe Ariès. Desde então, nada mais na França, e é então que a notoriedade internacional do historiador não cessa de crescer, como se pode medir pelas numerosas traduções de suas diferentes obras. A fim de explicar este recuo no plano editorial, é preciso considerar a apresentação dos três textos publicados dede 1986, todos precedidos de longos prefácios, visando situar a obra de P. Ariès.

Apenas a obra principal de Philippe Ariès que ainda não foi reeditada, Le Temps de l'histoire (Self, 1954), é finalmente retomada pela editora Seuil quando um projeto para a editora Albatros, para a qual Philippe Ariès já havia redigido um prefácio, não se finalizou. ${ }^{23}$ Esta reedição é provavelmente uma brecha na leitura apaziguadora do itinerário de Ariès.

O trabalho de apresentação é confiado a Roger Chartier, então diretor de estudos da EHESS, que reuniu uma parte dos arquivos Ariès no domicílio dele após sua morte. Valorizando a tese do pioneiro da escola dos Annales, Roger Chartier coloca em

\footnotetext{
22 « Lettre d'un métèque ", de J. Czapski à P. Ariès, sem data, final de 1961 (Arquivos P. Ariès).

${ }^{23} \mathrm{Cf}$. o prefácio a este projeto da reedição, reproduzido por R. Chartier sob o título « Le Temps de l'histoire » in P. Ariès, Essais de mémoire 1943-1983, op. cit., p. 45-58.
} 
formar uma opinião, Roger Chartier reforça a tese da ruptura ao utilizar numerosas passagens da autobiografia intelectual de Philippe Ariès, Un Historien du dimanche (1980).

Aliás, o autor do prefácio explora a pasta de Le Temps de l'histoire, composta da correspondência e das recensões, a qual lhe permite situar a recepção da obra da qual ele publica em anexos a lista, assim como uma entrevista de P. Ariès para Aspects de la France $^{24}$. Embora a recepção mostre a importância das publicações realistas ou tradicionalistas, Roger Chartier insiste na ideia de que este livro constitui uma ruptura intelectual de Philippe Ariès com seu meio de origem, explicando que Le Temps de I'histoire decepcionaria a comunidade maurrasiana: "[...] Ariès pretendia romper com os hábitos intelectuais de sua família política, assim como, alguns anos antes, em plena guerra, ele se afastara de Maurras e da Action française". ${ }^{25}$

No fim, mesmo que a introdução e os anexos de Le Temps de l'histoire mostrem uma visão mais histórica do que a narrativa de um Historien du dimanche, dois anos após a morte do historiador, a dinâmica da figura do historiador midiático da morte joga plenamente, na sua recepção, com a imagem do dossiê que lhe dedica, em abril de 1986, a revista $L I R E^{26}$. A publicação mensal literária dirigida por Bernard Pivot lhe oferece cinco páginas com, segundo a fórmula da revista, grandes excertos do livro acompanhados de duas belas fotografias que privilegiam a intimidade da família do historiador: a primeira amostra-a em 1925 com as quatro crianças, Philippe, Jacques, Georges e Marie-Rose, e a segunda mostra o futuro historiador, em férias em Archachon, na propriedade da família, com sua futura esposa, Primerose de Saint-Martin e amigos de infância.

\footnotetext{
${ }^{24}$ Cf. « Annexe II : Recensions et mentions du Temps de l'histoire » et « Annexe III : entretien entre P. Ariès et Michel Vivier, Aspects de la France, 23 avril 1954 », in Le Temps de l'histoire, op. cit., pp. 252-254.

${ }^{25}$ Roger Chartier, «L'amitié de l'histoire », in Le Temps de l'histoire, op. cit., p. 15.

${ }^{26}$ « Philippe Ariès : Le temps de l'histoire », Lire, abril de 1986, n 127, p. 58-62.
} 
$\mathrm{Na}$ introdução que precede o excerto, Philippe Ariès é apresentado como o homem dos paradoxos, combinando aspectos revolucionários com uma família realista:

“Um livro de Philippe Ariès é sempre uma festa e uma surpresa. [...] Realista pela razão e monarquista por temperamento quando a Universidade era marxista, ele foi reconhecido primeiro nos Estados Unidos antes de ser aclamado em seu próprio país $[\ldots]^{\prime 27}$

Sete anos mais tarde, Roger Chartier reedita, nos Essais de mémoire 1943-1993, dezoito textos de Philippe Ariès, assim como sua primeira obra, Traditions sociales dans les pays de France, publicado em 1943, que constitui o tomo escolhido deste volume. Como para Le Temps de l'histoire, este é precedido de uma sólida introdução cuja primeira parte evidencia os textos sociais em relação com a história das mentalidades em torno do suicídio, das atitudes diante dos portadores de necessidades especiais, da família e da cidade ou dos trabalhos manuais. Roger Chartier nos oferece um Philippe Ariès mais íntimo, "longe do recitativo da história política, longe dos pensamentos claros e das ideologias proclamadas" ${ }^{28}$ com a vontade de dar relevo aos « sentimentos involuntários e aos hábitos não expressos ». A exemplo do ângulo escolhido em Le Temps de l'histoire, o autor do prefácio insiste na ruptura que a história de Philippe Ariès realiza com a de um ambiente monarquista ou da tradição maurrasiana. Contudo, a segunda parte da introdução é mais nuançada, pois ela situa o contexto histórico das Traditions sociales dans les pays de France na França ocupada.

Reconstituindo, como em relação a Le Temps de l'histoire, o itinerário de Philippe Ariès e após ter situado a coleção "Cahiers de la restauration française" na qual é publicado o ensaio, Roger Chartier, que insiste nas filiações com M. Bloch, R. Dion e R. Boutruche, mantém ainda a tese da ruptura de Ariès com seus antigos mestres da Action française: "Relido hoje, o ensaio de Ariès surpreende, em primeiro lugar, por sua liberdade de tom e de análise, seja em relação à sua família política seja em relação à

\footnotetext{
${ }^{27}$ Ibid., p. 59.

${ }^{28}$ Roger Chartier, « Avant-propos », in Philippe Ariès, Essais de mémoire, op. cit., p. 11.
} 
Treze anos após a morte do historiador, em 1997, Le Présent quotidien, 1955-1966, ainda pela Seuil, constitui a apoteose desta redescoberta de seu itinerário político no momento da guerra da Argélia, mesmo que a escolha do título, Le Présent quotidien, privilegie o lado cronista do historiador atento aos fatos da vida quotidiana de preferência à dimensão ideológica e combativa dos artigos publicados na Nation française. Estes artigos são precedidos de um longo e minucioso prefácio de Jeannine Verdès-Leroux, então diretora de pesquisa do CNRS (CEVIPOF). Mostrando como o jornalista Ariès se repolitiza progressivamente no contexto da guerra da Argélia, sobretudo quando ressurge seu antigaulismo alimentado pela perseguição dos membros da OAS, e isto quando a Nation française apoia oficialmente De Gaulle, Jeannine VerdèsLeroux aponta a singularidade da posição de Ariès na Nation française intitulando aliás seu prefácio "La fidélité inventive de Philippe Ariès" 30 , retomado do In memoriam de Michel Foucault, em 17 de fevereiro de 1984, no Nouvel Observateur. Por isso, apoiando-se em um excerto de uma carta de Joseph Czapski, reproduzida no Historien du dimanche, que estigmatiza a cegueira de toda uma direita em torno da guerra da Argélia e em particular a da Nation française, a historiadora se interroga sobre a força de uma cultura política: “Que Philippe Ariès, cuja probidade era saudada por Joseph Czapski, não tenha visto todo o conteúdo e o alcance da revista esclarece o que é o engajamento político"31. Dito isto, a correspondência de Ariès com Czapski mostra como o pintor polonês abriu os olhos do historiador sobre a tortura, a ponto de conseguir o reconhecimento de Pierre VidalNaquet.

\footnotetext{
${ }^{29}$ Ibid., p. 15.

30 Jeannine Verdès-Leroux, « La « fidélité inventive » de Philippe Ariès », introduction, Le Présent quotidien, op. cit., p. 7-38.

${ }^{31}$ Ibid., p. 26.
} 
Tal desnudamento de uma cultura política em estado bruto, e não mais apresentada como no Historien du dimanche, conturba a recepção e a memória de Ariès, constituindo um bloco homogêneo com as duas reedições precedentes.

\section{Uma recepção conturbada, tensões com a memória política}

Numa pequena nota publicada no Le Monde, o historiador Jean-Pierre Rioux se mostra cético acerca da utilidade de publicar esses artigos que, segundo ele, não abrem caminhos, dizendo ao mesmo tempo que não já não se quer seguir um $P$. Ariès “prisioneiro de sua cultura"32. Na resenha da Histoire, de outubro de 1997, o autor, evidenciando o não conformismo e o brilhantismo dessas crônicas, faz questão de precisar que algumas tomadas de posição de Ariès nem sempre são defensáveis. Contudo, o golpe mais duro vem de Emmanuel Le Roy Ladurie, num artigo do Le Figaro littéraire que qualifica Philippe Ariès como "grande espírito frequentemente equivocado e por vezes aloucado, mas extraordinariamente engenhoso e sutil, com lampejos de genialidade" 33 . O autor do artigo estigmatiza o antigaulismo mórbido de Ariès que conduz este último a falar "não sem excesso de uma segunda depuração (Anti-OAS) por comparação com a primeira depuração, aquela de 1944, da qual ele abomina as exações". “A este respeito, pergunta-se E. Le Roy Ladurie, Ariès, se ele ainda estivesse vivo, falaria de uma terceira depuração acerca dos atuais processos Touvier e tutti quanti?"34.

Paralelamente à análise de Emmanuel Le Roy Ladurie que deve ser situada no contexto dos anos 90, atravessado pela síndrome de Vichy, a cultura política de Ariès emerge como objeto historiográfico com o artigo do historiador americano Patrick $\mathrm{H}$. Hutton, "The postwar politic of Philippe Ariès", (Journal of Contemporary History, 1999), logo seguido por uma obra, Philippe Ariès and the Politics of French Cultural History, (University of Massachusetts Press, 2004) compilações de artigos. As diferentes entradas temáticas são aí analisadas na medida da influência da herança política de Philippe Ariès

\footnotetext{
32 Jean-Pierre Rioux, « Philippe Ariès, chroniqueur du jeudi », Le Monde, 23 de maio de 1997.

33 Emmanuel Le Roy Ladurie, « Philippe Ariès : un Historien en réaction », op. cit..

34 Ibid..
} 
nossa monografia para o diploma de estudos aprofundados, intitulada Philippe Ariès, un réactionnaire authentique: itinéraire d'un maurrassien non-conformiste de l'Etudiant français à la Nation française, optamos pelo ângulo biográfico, reconstituindo o itinerário político posto em relação com o nascimento da vocação de um historiador, numa tese de doutorado, defendida em 2002, valorizando o que chamamos de um" tradicionalista nãoconformista". Sua publicação, em 2008, numa versão condensada, permitiu integrar uma parte do inventário de seus arquivos anexada à nossa tese.

A despeito das dificuldades encontradas para publicar a nossa tese, e quando Pierre Vidal-Naquet se envolveu pessoalmente, um pouco antes de sua morte, para fazer que fosse editada, a sua edição pelas Presses Universitaires du Septentrion, graças ao apoio de Michel Leymarie, foi acolhida muito além das revistas universitárias, em numerosos periódicos, sobretudo de direita (do Le Figaro ao Valeurs Actuelles) ou perpetuando uma cultura realista ${ }^{35}$, embora Emmanuel Laurentin Ihe tenha dedicado um programa da Fabrique de l'histoire, na France Culture, em 18 de fevereiro de 2009, dentro da programação da semana da infância.

Esta confusão entre a memória do militante e a do historiador estaria na origem do apagamento relativo de Philippe Ariès do plano historiográfico da França? Em todo caso, desde 1997 com Le Présent Quotidien, nada de novo foi reeditado, com exceção dos seus clássicos na coleção de bolso "Point histoire" da Seuil.

O primeiro colóquio acerca de Philippe Ariès, organizado em maio de 2009 em Toulouse, por iniciativa de Sylvie Mouysset, Jean-François Soulet e por nós, integra em sua programação, entre história, homenagem e amizade, esta questão da memória política, no plano historiográfico. Ela se traduz, pela primeira vez, na família, pelo testemunho de Jacques Ariès, sobrinho do historiador, que encontra, com o recuo que o

\footnotetext{
${ }^{35} \mathrm{Cf}$. entre outros, Antoine Clapas, «Philippe Ariès, au service de l'histoire », Les Epées, juin 2008 ; Vincent Gaillères, « Ariès contre-révolutionnaire », Action française 2000, 16 de setembro 2009.
} 
seu tio estabelece, no Historien du dimanche, uma versão um pouco passadista da vida em família dos Ariès, excessivamente tradicionalista. Apoiando-se nos excertos das memórias de Emile Ariès, pai de Philippe Ariès, escritos entre 1964 e 1970 dos quais ele está em posse, Jacques Ariès propõe uma cativante releitura do primeiro capítulo do Historien du dimanche, mostrando que a vida em família está banhada numa atmosfera de progresso e de cultura técnica. Em apoio dos excertos das Memórias do pai do historiador, são acrescentados documentos iconográficos sobre o universo familiar do historiador ${ }^{36}$. Assim, o uso dos arquivos Ariès, que contribuiu para evidenciar, no plano historiográfico, a articulação entre cultura política e vocação de historiador, suscita outros arquivos familiares que talvez possam ser um dia juntados ao corpus dos Arquivos nacionais.

Enfim, de nossa parte, privilegiando a criança como objeto historiográfico ${ }^{37}$, nós desenvolvemos desde 2009 um site dedicado ao historiador ${ }^{38}$, organizado em torno de quatro rubricas : 1) Atualidades; 2) A obra ; 3) Philippe Ariès em seu tempo; 4) Trabalhos e estudos. Ele visa sobretudo mostrar todas as facetas de sua obra, desde a demografia até a morte, passando pela infância, a educação, e a vida privada, propondo o mais possível excertos e multiplicando os pontos de vista daqueles que foram seus contemporâneos ou seus discípulos.

\footnotetext{
${ }^{36}$ Cf. Jacques Ariès, "Une relecture familiale du premier chapitre d'Un Historien du dimanche », Cahier d'histoire immédiate, op. cit., pp. 71-89.

${ }^{37} \mathrm{Cf}$. Guillaume Gros, « Philippe Ariès : naissance et postérité d'un modèle interprétatif de l'enfance », Histoire de l'Education, $n^{\circ}$ 125, 2010.

${ }^{38}$ Endereço: http://philippe-aries.histoweb.net/.
} 
Recebido em: 02/12/2012 Aprovado em: 01/04/2013

Universidade do Estado de Santa Catarina - UDESC

Programa de Pós-Graduação em História - PPGH

Revista Tempo e Argumento

Volume 05 - Número 09 - Ano 2013

tempoeargumento@gmail.com 